\title{
O ATO EDUCATIVO NA EDUCAÇÃO INFANTIL SOB A ÓTICA DA PEDAGOGIA HISTÓRICO-CRÍTICA
}

\author{
Larissa Aparecida Trindade ${ }^{1}$, Célia Maria Guimarães ${ }^{2}$ \\ ${ }^{1}$ Doutorado em Educação pela Universidade Estadual Paulista - UNESP, Campus de Presidente Prudente. Docente da \\ Faculdade de Presidente Prudente - FAPEPE. E-mail: larissatrindadepef@yahoo.com.br \\ ${ }^{2}$ Doutora em Educação pela Universidade Estadual Paulista - UNESP. Pós Doutorado pela Universidade de Lisboa- \\ Portugal e pela Escola Superior de Educação do Instituto Politécnico de Santarém-PT. Docente do Programa de Pós- \\ Graduação em Educação da Universidade Estadual Paulista - UNESP. E-mail: celiamguimaraes@terra.com.br
}

\section{RESUMO}

Este artigo é resultado da tese de doutoramento denominada "A brincadeira de papéis sociais como elemento orientador da formação continuada de uma professora pré-escolar", na qual o objetivo central foi realizar e refletir sobre o processo de formação continuada da professora pré-escolar por meio de intervenções teóricas e práticas para a construção de uma prática educativa humanizadora norteada na Psicologia Histórico-Cultural, na Pedagogia Histórico-Crítica e no emprego do brinquedo e da brincadeira de papéis sociais na situação escolar. Para esta discussão trouxemos uma breve apresentação da Pedagogia Histórico-Crítica, envolvendo o âmbito social e os objetivos de sua construção, assim como seus fundamentos e características particularmente relacionadas ao ensino na Educação Infantil. Também destacamos o papel do professor, a formação continuada docente e a organização da prática educativa à guisa do materialismo histórico-dialético. Para tanto, utilizamos o método materialista histórico-dialético e os instrumentos metodológicos: questionário, entrevista, observação e análise dos documentos municipais para desenvolvimento da pesquisa, a qual revelou que as propostas educativas da professora oscilaram durante o processo formativo, pois ora seguiam os pressupostos marxistas, ora reproduziam práticas educativas do Ensino fundamental. Concluímos assim, que os professores carecem de uma visão de Educação Infantil como espaço promotor do desenvolvimento omnilateral da criança e de uma compreensão das crianças como sujeitos sociais em construção, frutos das suas relações humanas, com tempos distintos para aprender e níveis diferentes de desenvolvimento, especialmente, ensinar que a brincadeira de papéis sociais é a atividade-guia para o processo de humanização das crianças pré-escolares. Palavras-chave: Educação Infantil; Formação Continuada; Materialismo Histórico-Dialético.

\section{EDUCATVO ACT IN CHILD EDUCATION UNDER THE VIEW OF HISTORIC-CRITICAL PEDAGOGY}

\section{ABSTRACT}

This article is the result of a doctoral dissertation called "The play of social roles as a guiding element of the continuing education of a preschool teacher", in which the main objective was to realize and reflect on the process of continuing education of the preschool teacher by through theoretical and practical interventions for the construction of a humanizing educational practice based on Historical-Cultural Psychology, on Historical-Critical Pedagogy and on the use of toys and the play of social roles in the school situation. For this discussion we bring a brief presentation of the Historical-Critical Pedagogy, involving the social scope and the objectives of its construction, as well as its foundations and characteristics particularly related to early childhood education. We also highlight the role of the teacher, continuing teacher education and the organization of educational practice in the guise of historical-dialectical materialism. For this, we used the historical-dialectical materialist method and the methodological instruments: questionnaire, interview and observation and analysis of municipal documents for the development of the research which revealed that the teacher's educational proposals oscillated during the formative process, because now they followed the Marxist assumptions, sometimes reproduced educational practices of elementary school. We conclude that teachers lack a vision of early childhood education as a space that promotes the omnilateral development 
of children and an understanding of children as social subjects under construction, fruits of their human relationships, with different times to learn and different levels of development, especially, teaching that social role play is the guiding activity for the humanization process of preschool children.

Keywords: Early Childhood Education; Continuing Education; Historical-Dialectical Materialism.

\section{EL ACTO EDUCATIVO EM EDUCACIÓN INFANTIL BAJO LA ÓPTICA DE LA PEDAGOGÍA HISTÓRICO-CRÍTICA}

\section{RESUMEN}

Este artículo es el resultado de una disertación doctoral llamada "El juego de roles sociales como elemento guía de la educación continua de un maestro de preescolar", en el cual el objetivo principal era realizar y reflexionar sobre el proceso de educación continua del maestro de preescolar a través de intervenciones teóricas y prácticas para la construcción de una práctica educativa humanizadora basada en la psicología histórico-cultural, en la pedagogía histórico-crítica y en el uso de juguetes y el juego de roles sociales en la situación escolar. Para esta discusión traemos una breve presentación de la Pedagogía Histórico-Crítica, involucrando el alcance social y los objetivos de su construcción, así como sus fundamentos y características particularmente relacionadas con la educación de la primera infancia. También destacamos el papel del profesor, la formación continua del profesorado y la organización de la práctica educativa en forma de materialismo histórico-dialéctico. Para esto, utilizamos el método materialista histórico-dialéctico y los instrumentos metodológicos: cuestionario, entrevista y observación y análisis de documentos municipales para el desarrollo de la investigación que reveló que las propuestas educativas del profesor oscilaron durante el proceso formativo, porque ahora seguían los supuestos marxistas, a veces reproducen prácticas educativas de la escuela primaria. Concluimos que los maestros carecen de una visión de la educación de la primera infancia como un espacio que promueve el desarrollo omnilateral de los niños y la comprensión de los niños como sujetos sociales en construcción, fruto de sus relaciones humanas, con diferentes momentos para aprender y diferentes niveles de desarrollo, especialmente, enseñar que el juego de roles sociales es la actividad guía para el proceso de humanización de los niños en edad preescolar.

Palabras clave: Educación Infantil; Educación Continua; Materialismo Histórico-Dialéctico.

\section{INTRODUÇÃO}

\begin{tabular}{llr}
\multicolumn{1}{c}{ Neste } & material & apresentamos \\
sinteticamente os & pressupostos da & Pedagogia \\
Histórico-Crítica, & especificamente & aqueles \\
voltados ao ensino na Educação Infantil.
\end{tabular}

A Pedagogia Histórico-Crítica ao se preocupar com o processo de emancipação humana, é uma vertente educativa que busca, por meio da união e da conscientização dos docentes, lutar pela socialização dos conhecimentos mais elaborados sem segregação de classes e por uma escola igualitária que garanta os mesmos direitos de acesso a cultura científica, artística e filosófica à classe trabalhadora, tendo em vista que:

\footnotetext{
A classe dominante não coloca a escola a serviço da imposição da assim chamada cultura burguesa a toda a população porque, do mesmo modo
}

\begin{abstract}
que o capital é riqueza humana transformada em propriedade privada da burguesia, a assim chamada cultura burguesa é riqueza intelectual humana posta a serviço dos interesses de uma classe social (DUARTE, 2016, p. 26).
\end{abstract}

Por essa razão, a Pedagogia HistóricoCrítica visa o rompimento do modelo de educação dominante, defendido pelo Estado, o qual há muitos anos vem cumprindo o seu papel em relação a uma pequena parcela da população pertencente à classe burguesa, cujos interesses são defendidos e mantidos por um sistema educativo dual e classificatório.

Nessa mesma linha de raciocínio, questiona-se a Educação Infantil, historicamente marcada por um ensino, ora preparatório, ora espontaneísta e desescolarizante. 
conhecimento científico nessa etapa escolar, numa perspectiva burguesa, é tido como dispensável, destinado apenas a partir do ingresso no Ensino Fundamental. Assim, práticas de caráter científico, na maioria das vezes, são encaradas como algo pejorativo e massacrante, como ações nocivas à formação infantil. Conforme destaca Arce (2013, p. 06):

[...] as políticas públicas para a educação de crianças pequenas bem como a produção hegemônica na área apontam para qualquer tentativa de intervenção intencional, direta por parte do adulto no desenvolvimento infantil como quase um verdadeiro sacrilégio. Algo que feriria a alma infantil.

Saviani (2011) e Lombardi (2013) destacam que a diferença existente entre esses níveis de ensino está reportada às formas e aos préstimos das mediações e não na relação livre versus sistematizado.

A concepção biologizante de educação secundariza $o$ ato de ensinar, desconsiderando essas ações como formas de apropriação do gênero humano, conforme reforça Duarte (2000; 2010). Essa vertente defende o desenvolvimento infantil como um florescimento, enfatizando o aspecto biológico para a constituição dos sujeitos e pressupondo, para tanto, o mínimo de intervenções possíveis, ao alegar prejuízos à formação qualitativa das crianças.

Esse modelo de Educação Infantil coloca apenas as crianças como o eixo do processo pedagógico, como definidoras primárias das propostas e dos objetivos das práticas, visto que estas práticas apresentam caráter não diretivo, mas de satisfação dos interesses imediatos das crianças. Acredita-se que as crianças aprendem sozinhas no contato com a cultura e com seus pares.

Esse

biologizante/espontaneísta educação), de acordo com Arce (2013), é endossado pelos Referenciais Curriculares Nacionais da Educação Infantil - RCNEI (BRASIL, 1998), que atribui à escola a função de complementação da educação familiar. Aos professores, o documento destaca o papel de meros auxiliares, de acompanhantes das realizações infantis e o brincar espontâneo como forma essencial para o desenvolvimento integral infantil.

A Pedagogia Histórico-Crítica e a Psicologia Histórico-Cultural, em contrapartida, defendem o ensino e a escolarização desde a Educação Infantil, por acreditarem que o processo de humanização depende essencialmente do acesso aos bens culturais e científicos da humanidade. Advogam, sobretudo, que é papel da escola e do ato educativo do professor promover o desenvolvimento das funções psíquicas superiores infantis. Sobre essa temática Martins (2011, p. 54) pontua que:

[...] a posse, por parte de cada indivíduo singular, dos atributos humanos, no que incluem as plenas possibilidades do pensamento, é processo socialmente dependente. Para isso ocorrer, contudo, demanda que forças objetivas operem a esse favor. Tal como postulado com a pedagogia históricocrítica, operar nessa direção é função precípua da educação escolar, a quem compete a tarefa de ensinar, isto é, promover a socialização dos conhecimentos

representativos das máximas conquistas científicas e culturais da humanidade, por meio da prática pedagógica, tornando a realidade inteligível.

Vigotski $^{1}$ (1991), por sua vez, aponta que o desenvolvimento das funções psicológicas superiores (FPS) ${ }^{2}$ é decorrente do processo de internalização que se configura na apropriação

\footnotetext{
1 o nome Vigotski é encontrado, na bibliografia existente, escrito das mais variadas formas, dentre elas, destacamos Vigotski, Vigotski, Vigotskii, Vigotskji, Vygotski, Vigotsky. Entretanto, neste estudo decidimos empregar a grafia Vigotski, preservando, contudo, nas indicações bibliográficas, a grafia adotada em cada uma delas (DUARTE, 1996, p. 18).
} 
ativa dos elementos ${ }^{2}$ sociais, históricos e culturais. Como o próprio autor expõe: "é a reconstrução interna de uma operação externa" (VIGOTSKI, 1991, p. 63). Por essa visão, inicialmente, os sujeitos se relacionam com as pessoas e com os objetos nas diferentes instâncias sociais (processo interpsíquico) e, durante e/ou após essa relação, passam a interpretar ativamente os aspectos sociais (processo intrapsíquico), desencadeando a sua formação humana. Para ele, a cultura é considerada assim, determinante no processo de formação dos indivíduos.

O sujeito, portanto, para a sua efetiva humanização, necessita da mediação dos signos culturais, que, de acordo com Martins (2013, p. 46), "[...] é a interposição que provoca transformações, encerra a intencionalidade socialmente construída e promove desenvolvimento, enfim, uma condição externa que, internalizada, potencializa o ato de trabalho seja ele prático ou teórico".

Para as teorias adotadas nesta tese, cultura é toda ação produtiva humana sobre a natureza é o resultado de toda ação humana sobre a natureza para produzir sua existência, satisfazer suas necessidades e para garantir sua sobrevivência.

Duarte e Martins (2013, p. 51), apoiados em Leontiev, apontam ainda que a cultura é produto das atividades realizadas pelos homens ao longo dos anos, é "o patrimônio humano genérico como universo de objetivações disponibilizadas ao enriquecimento da atividade humana e, consequentemente, ao desenvolvimento das potencialidades e capacidades dos indivíduos". Ressaltam, entretanto, que por vivermos numa sociedade de classes, e esta se constituir em princípios como desigualdade social, desigualdade de direitos, esta produção humana não é disponibilizada a todos os indivíduos igualmente, o que impede a uma grande parcela da população de alcançar seu processo de humanização. Vale ressaltar que a não socialização do patrimônio cultural a todos os membros do gênero humano caracteriza o processo de alienação.

\footnotetext{
2 [...] são aquelas funções mentais que caracterizam o comportamento consciente do homem: sua atenção voluntária, percepção, a memória e pensamento, este último, constitui uma perspectiva metodológica que chama nossa atenção para a compreensão de diversos aspectos da personalidade do homem (VIGOTSKI, 1991, p. 64).
}

A Pedagogia Histórico-Crítica, por isso, é contrária às visões pedagógicas infantis liberais e espontaneístas que se aliam ao viés burguês, seja por omissão ou sustentação, centrando-se, portanto, em propostas educativas humanizadoras e revolucionárias. Defende ainda as instituições de Educação Infantil como espaços educativos que devem se adiantar ao processo de desenvolvimento das crianças e, para isso, exige um planejamento pedagógico intencional e sistematizado, bem como profissionais competentes, engajados nesse propósito libertador, pois, conforme aponta Saviani (2013, p. 13),

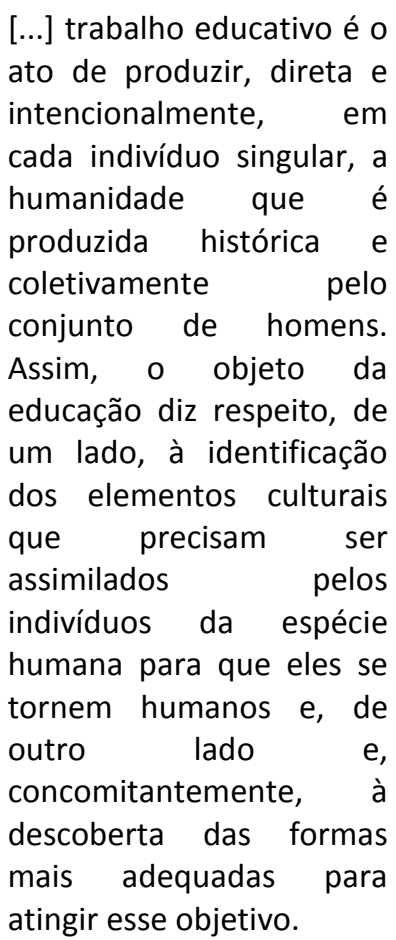

A concepção marxista, nesse panorama, assevera que esta forma e intencionalidade de ensino deve ser garantida às crianças desde a Educação Infantil, sobrepujando o papel atual destas instituições como centros de assistência ou convivência de crianças a instâncias de respeito à diversidade, à justiça e à emancipação social. Deste modo, opõe-se às concepções espontaneístas de educação, as quais acreditam que o papel do professor é o de mero organizador do espaço pedagógico, conforme argumentam Prado e Azevedo (2012, p. 49):

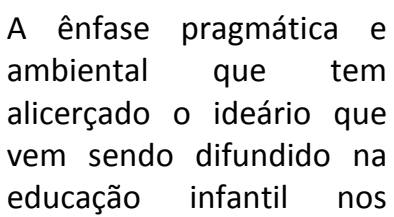


incita a pensar no professor como um "mero protetor" dos "direitos" da infância. Por conseguinte, a instituição que esta frequenta não seria uma escola e sim um espaço de vivência, um lugar livre, no qual as crianças estarão protegidas das mazelas do mundo adulto.

Essa abordagem teórica desacredita, sobretudo, que a criança já nasce dotada de todas as suas capacidades humanas, que 0 desenvolvimento infantil ocorre naturalmente na ação da criança com o objeto durante a atividade, sem processo de intervenção e que a mediação do professor pode atrapalhar esse processo evolutivo.

Nereide Saviani (2012, p. 71, grifos da autora) amplia nossa discussão, esclarecendo:

\section{[...] que a educação infantil, se imbui do caráter de educação escolar [...] voltada para a formação integral da personalidade humana. Por conseguinte, ela comporta, sim um currículo. Não no sentido de "grade" de matérias, mas como conjunto de atividades nucleares, intencionalmente \\ planejadas sistematicamente \\ desenvolvidas, de acordo com as características da faixa etária e com as necessidades e condições concretas das crianças as quais se destinam.}

A autora ressalta que a etapa da Educação Infantil deve ser dotada de um currículo capaz de ampliar o universo cultural da criança e contribuir para uma formação ampla orientada por uma concepção igualitária de mundo. Para tal, esse currículo precisa ser constituído por um conjunto de atividades nucleares, que tenha "[...] por eixo estruturante $a$ formação da visão científica do mundo, a análise concreta da realidade" (NEREIDE SAVIANI, 2012, p. 75 , grifos da autora).
A concepção de currículo assumida pela Pedagogia Histórico-Crítica, nesse aspecto específico, se aproxima, da visão de currículo exibida pelas Diretrizes Curriculares Nacionais para a Educação Infantil - DCNEI (BRASIL, 2010), como um "conjunto de práticas que buscam articular as experiências e os saberes das crianças com os conhecimentos que fazem parte do patrimônio cultural, artístico, ambiental, científico e tecnológico, de modo a promover o desenvolvimento integral de crianças de 0 a 5 anos de idade (BRASIL, 2010, p.12).

Amparados, portanto, na Pedagogia Histórico-Crítica e nas DCNEl, é possível afirmar que as escolas, ao deixarem de ofertar os conhecimentos mais elaborados às crianças, concomitantemente negam uma formação humana efetiva, recusam a compreensão dos mecanismos de dominação e, consequentemente, colaboram para a manutenção dos processos de exploração. Como não há escola neutra, tampouco conteúdos curriculares neutros, logo toda ação educativa é marcada por interesses ideológicos de classes.

O educador, assim, mesmo que inconscientemente, trabalha aliado a um ideal de classe. Para Saviani (2011, p. 12), é primordial que o educador tenha "[...] consciência disso para trabalhar as diferentes concepções, possibilitar aos alunos sua apropriação crítica e desenvolver a luta de ideias, porque o conhecimento se forma e avança no debate, na polêmica".

A escola, na perspectiva histórico-crítica, é uma instância construída culturalmente para desenvolver o processo de trabalho pedagógico, de contribuir para o processo de humanização dos sujeitos e, para tal, requer trabalhar os conhecimentos científicos, artísticos e filosóficos, os quais as crianças dificilmente teriam acesso em outros ambientes sociais, articulando-os às metodologias adequadas aos níveis de desenvolvimento de cada sujeito.

Saviani (2013) complementa, expondo que o conteúdo a ser trabalhado na escola pelo professor demanda ser algo diferente daquele que a criança vivencia cotidianamente, fora dos muros escolares; caso contrário, não haveria necessidade de uma instituição especializada no processo de ensino e aprendizagem infantil. Para um ensino adequado, o autor aponta ainda que é necessário considerar os conhecimentos prévios da criança, mas caminhar para superação destes conhecimentos do senso comum em direção à internalização dosconhecimentos científicos 
sistematizados. Nesse mesmo sentido, Arce (2013, p. 32) esclarece que:

Ao tomar a escola como lócus privilegiado do saber sistematizado, afastamos a mesma do cotidiano, não significando que este será ignorado. O dia a dia das crianças e toda a bagagem oriunda deste, assim, constituir-se-ão apenas em pontos de partida a serem superados. A escola passa a ser um momento de suspensão da vida cotidiana, para isso, artificializa-se, apresentase como um ambiente criado, planejado pelos adultos que, intencionalmente, educam as crianças em seu interior. O principal direito a ser respeitado nessa instituição, no entanto, é o direito ao conhecimento. Direito esse propulsor do desenvolvimento infantil.

Assim sendo, os representantes da presente teoria não se intimidam em afirmar que a Educação Infantil se constitui num nível de educação escolar, de transmissão de conhecimento científico e nem em considerar as crianças como alunos, como aprendizes. A preocupação basilar dessa vertente sobre o currículo se justifica no pleno processo de formação infantil, que depende sumariamente da qualidade das interações e das aprendizagens sociais realizadas pelas crianças. Nesse aspecto, Saviani (2011, p. 45) ressalta, sobretudo, que:

\begin{tabular}{|c|c|}
\hline \begin{tabular}{l}
\multicolumn{1}{c}{ sem } \\
evantes, \\
nificativos, \\
endizagem \\
stir, ela trar \\
m arreme \\
nsforma-se $n$ \\
l porque o d \\
tura \\
trumentos \\
ispensáveis
\end{tabular} & $\begin{array}{l}\text { conteúdc } \\
\text { conteúdo } \\
\text { deixa d }\end{array}$ \\
\hline
\end{tabular}

não se liberta se ele não vier a dominar aquilo que os dominantes dominam. Então, dominar o que os dominantes dominam é condição de libertação.

Não é sem razão que as teorias adotadas, Pedagogia Histórico-Crítica e Psicologia HistóricoCultural, destacam que, para não haver uma formação ingênua e alienada, cabe à escola e ao professor trabalharem para o desenvolvimento do pensamento crítico e concreto nas crianças.

0 ensino deve constituir-se como processo consciente, deliberado, sistemático e metódico, voltado para uma dupla função: servir como fonte de informação e contribuir para organizar a atividade cognoscitiva dos estudantes. A elevação do nível de pensamento torna-se um dos requisitos fundamentais para colocar as gerações atuais no nível do nosso tempo e a educação escolar destaca-se como a principal responsável por esta tarefa (SAVIANI, 2012, p. 61).

A Pedagogia Histórico-Crítica assegura que a forma humana de ser apresenta suas raízes nos aspectos históricos e sociais, sendo marcada pela sociedade em que o sujeito vive. Por este motivo, torna-se evidente que nos constituímos pelos outros, somos reflexos da realidade na qual estamos inseridos. Contudo, Vigotski (1996) destaca que o conceito de reflexo, empregado pela teoria, não se remete à apropriação literal da realidade, ou seja, os sujeitos não são cópias fiéis do contexto, como acreditam as correntes empiristas. Contrariamente, concebe que estes são autores de seu processo de formação, pois apresentam participação ativa nessa relação com outros sujeitos e objetos, podendo, desse modo, acatar, refutar ou transformar a realidade posta.

Desse modo, o objetivo central da pesquisa foi realizar e refletir sobre o processo de formação continuada da professora pré-escolar por meio de intervenções teóricas e práticas para a construção de uma prática educativa humanizadora norteada na Psicologia HistóricoCultural, na Pedagogia Histórico-Crítica e no emprego do brinquedo e da brincadeira de papéis sociais na situação escolar.

\section{MÉTODO}

O método materialista histórico-dialético guiou o processo de formação de formação continuada junto a professora participante para a 
construção de práticas educativas norteadas pelas Psicologia Histórico-Cultural e pela Pedagogia Histórico-Crítica, bem como pelo emprego na situação pré-escolar do brinquedo e da brincadeira de papéis sociais.

Mediante a aprovação do Comitê de ética (protocolo no 2.877.925) e a autorização dos respectivos responsáveis pelo município, começamos a investigação in loco para conhecermos a realidade particular. Reunimos os dados iniciais a partir do estudo do documento oficial da Divisão Municipal de Educação e Cultura - Guia Curricular de Ensino Municipal (2010) e do plano anual de Ensino Pré-escolar (2016). Seguidamente, procedemos à observação das práticas educativas da professora parceira e embasados numa pré-análise desta ação observatória, organizamos um roteiro de questionário socioeconômico e de uma entrevista semiestruturada para aprofundarmos os dados.

A escolha de diferentes instrumentos metodológicos se fez necessária para ampliarmos o número de informações e possibilitar uma maior segurança durante a organização do processo de formação continuada.

O processo de formação continuada ocorreu em encontros semanais e/ou quinzenais, conforme a agenda da professora, nos horários destinados regimentalmente à sua hora de estudos na jornada semanal de trabalho.

$\mathrm{Na}$ etapa inicial do processo formativo socializamos os resultados das análises realizadas (questionário, entrevista e observação) e posteriormente, começamos o percurso de leituras e discussões dos textos e vídeo-aulas, cujos critérios de seleção pautaram-se nas carências formativas da professora sobre a teoria que sustentava a formação continuada. Essa etapa constitui-se em seis sessões de trocas de pontos de vista e explicações de conceitos, as quais foram gravadas e transcritas para facilitar a continuidade do processo formativo.

Seguindo o processo de formação continuada teórico, planejamos ainda, as práticas humanizadoras junto às crianças pré-escolares, as quais foram elaboradas, gradualmente (pela professora e pesquisadora no primeiro momento e em seguida, apenas pela professora préescolar) a partir da identificação das necessidades infantis, da identificação dos objetivos pretendidos, bem como das descrições das vivências das crianças.

\section{RESULTADOS E DISCUSSÕES}

A partir dos resultados do processo de formação continuada podemos perceber que as relações sociais são os elementos centrais no contexto educativo, as quais se efetivam nas relações entre professor e crianças e crianças em si, cada qual com seu nível de compreensão sobre o mundo. Os professores, com sua visão sintética sobre a realidade, organizam o ensino a partir da prática social comum a ambos (professores e crianças) e objetivam a evolução da compreensão sincrética infantil.

De acordo com Costa (2009, p. 70-71):

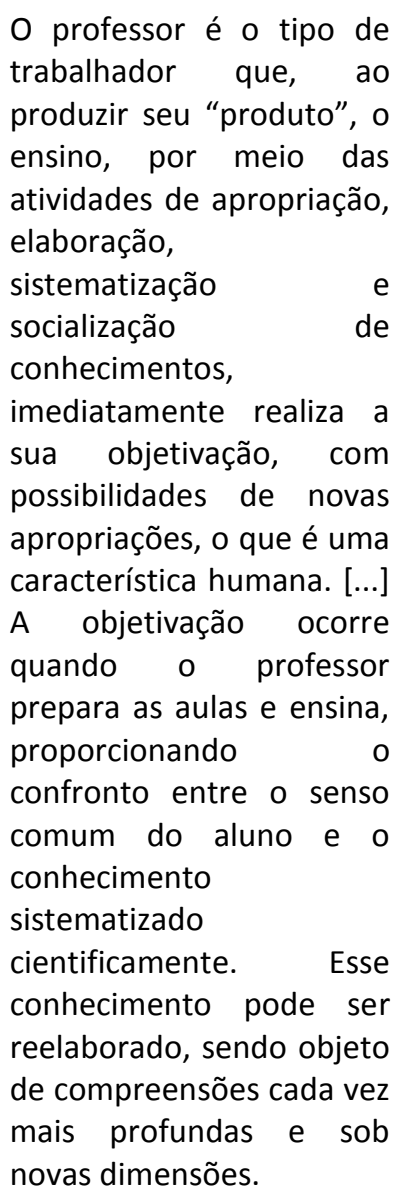

Os professores de Educação Infantil são sujeitos imprescindíveis no contexto escolar e/ou social, pois seu papel é central no processo de humanização das crianças pequenas. Cabe a eles a complexa tarefa de escolher as versões mais desenvolvidas dos conteúdos/objetos de ensino a serem trabalhados, nos diversos campos do conhecimento científico, nas diversas disciplinas curriculares, tais como: Arte, Educação Física, Ciências, Geografia, História, Português e Matemática, etc., a partir dos processos mentais que almejam desenvolver nas crianças, além de determinar o tipo de atividade a ser proposta, estruturar o ambiente e analisar se a 
metodologia empregada na atividade proposta é adequada ou não ao seu motivo, para que a ampliação das experiências infantis sejam garantidas (EIDT; DUARTE, 2007).

Para Vigotski (1995), os conhecimentos científicos são sínteses históricas das produções materiais e intelectuais da humanidade, e para que as crianças possam apropriar-se dessas produções é necessária a ampliação qualitativa de suas generalizações conceituais (geradas ao pensamento pelo processo de aprendizagem), além de alterações das funções mentais e formações de novos níveis de desenvolvimento. Ressaltamos, sobretudo, que todas essas evoluções humanas são resultantes do trabalho intencional e efetivo do professor. Logo, a Psicologia Histórico-Cultural e a Pedagogia Histórico-Crítica apresentam a figura docente como um intelectual, como o sujeito socialmente mais capacitado, mais experiente para a transmissão do patrimônio histórico-cultural da humanidade e pela formação plena das faculdades mentais infantis, dentre elas: a linguagem, o pensamento, a imaginação, e a percepção. O professor trabalha para a criança realizar a transposição/superação dos conhecimentos espontâneos para os conhecimentos científicos, objetiva superar a capacidade de apenas se adaptar à realidade local para a conquista da capacidade de transformá-la.

$\mathrm{Na}$ perspectiva em discussão, os professores têm consciência (ou necessitariam ter) de que os processos de ensino e aprendizagem são fontes de desenvolvimento e "[...] momento intrinsecamente necessário e universal para que se desenvolvam na criança as características humanas não naturais (formadas historicamente)" (VIGOTSKI, 2001, p. 115). Em vista disso, sabem que não é qualquer proposta de ensino que promoverá o desenvolvimento global infantil. Também compreendem que para isso ocorrer o ensino precisa ser planejado cuidadosamente, com objetivos claros e abordagem metodológica coerente com as características infantis, considerando a ação ativa da criança no decurso da aprendizagem, seus interesses, necessidades e processos de desenvolvimento, bem como o papel da cultura na formação humana.

Para atingir esse nível de excelência, Facci (2004) explicita que o docente necessita estar em pleno desenvolvimento profissional, seja na formação inicial, continuada, seja individual e/ou coletivamente, embasado nas teorias pedagógicas, além de refletir sobre os avanços científicos, caso contrário, o trabalho educativo corre o risco de se aproximar do espontaneísmo e do cotidiano alienado da sociedade capitalista.

Saviani (2013) reitera que o trabalho docente demanda estudos do processo de ensino e aprendizagem e do desenvolvimento infantil para ser capaz de articular ações pedagógicas pautadas nos conteúdos clássicos (essenciais para o crescimento intelectual), nas formas e na realidade concreta da criança. Requer ainda um trabalho dialético com os conhecimentos cotidianos e os científicos, mantendo um olhar histórico e político sobre os objetos de estudo, conscientes do tipo de homem e de sociedade que almejam construir/desenvolver.

Contudo, sabemos que a realidade brasileira ainda se encontra distante de atingir esses patamares de formação docente para a Educação Infantil. Neste sentido Facci (2004, p. 244) adverte que:

[...] se os professores não
conseguem realizar a
atividade docente de
forma que provoque o
desenvolvimento das FPS,
acredito, juntamente com
Gallimore e Tharp (1996),
que é porque eles não
sabem como fazê-lo. Eles
não sabem, segundo esses
autores, porque nem
sempre foram ensinados.

Martins (2007) registra que no processo de formação docente há uma despreocupação com a transmissão dos conhecimentos historicamente acumulados, gerando um empobrecimento do desenvolvimento humano e uma crise na função social da escola na contemporaneidade. Saviani (2011), ao complementar essa visão, ressalta que esse modelo de educação esvaziado encara a escola como aparelho ideológico do Estado e trabalha na direção de reproduzir a desigualdade, a injustiça e exploração social.

De acordo com Mezáros (2008), essa crise do sistema público de ensino é intencional e segue as regras do capitalismo que propõe reforçar a divisão de classes e de manter no poder a burguesia. Não podemos nos esquecer que os futuros professores também são vítimas desse processo de formação tanto quanto as crianças, pois como pertencem majoritariamente 
à classe trabalhadora, sendo egressos da escola pública, optam por cursos de formação e/ou de qualificação mais curtos e mais baratos, acreditando que ingressarão mais rapidamente no mercado de trabalho.

Duarte (2010) aponta que esse modelo de educação, que secundariza o papel da escola e de seus conteúdos e prima pela empiria e a autoformação, trabalha em conformidade com os pressupostos neoliberais, segundo os quais os sujeitos são moldados às necessidades do mercado que exigem indivíduos flexíveis, submissos e multifacetários. Nessa lógica, inclusive 0 processo formativo torna-se responsabilidade individual, isentando o Estado e a classe dominante da oferta de condições adequadas ao desenvolvimento humano, dos problemas e injustiças sociais, culpabilizando exclusivamente os sujeitos de seu fracasso profissional e pessoal, por escolhas inadequadas e/ou ausência de esforços.

Nestes casos, os maiores prejudicados são, não só os professores, mas, especialmente as crianças que demandam ações educativas bem articuladas às especificidades de sua faixa etária para se emanciparem.

Com fundamento neste ponto de vista sobre as exigências formativas e seus condicionantes, sobre o papel do professor, nomeadamente $\mathrm{o}$ da Educação Infantil e motivados pelos desafios formativos dos docentes brasileiros e nas consequências destes para a sociedade, estruturamos o presente trabalho. O processo de constituição sucedeu, entre outras ações, fundamentalmente por meio de um processo de formação continuada de uma professora pré-escolar da rede pública municipal de ensino, ancorado nos aportes do materialismo histórico-dialético e no uso do brinquedo e da brincadeira no processo educativo como elementos humanizadores.

Pois, a formação docente brasileira, na contemporaneidade, segundo Duarte (2010), tem se afastado do conhecimento científico e ratificado a cotidianidade. Os professores, portanto, encontram-se frequentemente despreparados para o exercício profissional e confusos sobre o seu real papel social, pois não estão recebendo uma formação consistente, alicerçada nos conhecimentos culturais mais elaborados, possibilitadores de uma ação docente consciente e humanizadora.

A deficiência formativa dos professores, em geral, e daqueles da Educação Infantil, não se revela apenas em relação aos conteúdos referentes à brincadeira e ao brinquedo, mas remete-se a todo o processo formativo. Marin (1996 apud $\mathrm{FACCl}, 2004$ ) constatou, em uma análise da bibliografia brasileira, que, desde a década de 1950, os cursos de formação docente já apresentavam fragilidades. Assim, é recorrente encontrarmos professores sem o domínio mínimo das capacidades exigidas para a sua atuação profissional. Sobre esse assunto Marsiglia (2011, p. 63) reforça que:

[...] a formação de
professores torna-se
precária e no caso da
educação infantil leva o
dito atendimento de
qualidade às crianças
pequenas uma completa
falácia, afastando a
maioria dos educadores
de seu papel de
transmissor de
conhecimento, pois os
profissionais são
malformados (quando
formados!), sem domínio
técnico, compromisso
político ou qualquer tipo
de conhecimento teórico
que Ihes permita
desenvolver uma prática
pedagógica de qualidade.

Saviani (2011), por sua vez, destaca que os profissionais da educação no século XXI estão sendo preparados apenas para a prática, com métodos/estratégias de como fazer, isentas, na maioria das vezes, de sustentação teórica. Estão sendo formados, portanto, técnicos de educação e não docentes, os quais pressupõem a articulação entre teoria e prática em sua constituição.

A formação de professores técnicos e não de professores cultos é um dos dilemas da formação docente apresentados pelo autor, que afirma ser a mesma conduzida pelo princípio da redução de custos, haja vista que o processo formativo de um técnico é mais curto e menos dispendioso do que de um intelectual, conforme discute Duarte (2010, p. 22):

[...] a linha distintiva entre a escola como lócus do exercício profissional e a escola como lócus que 
deva preparar filosófica, teórica metodologicamente o professor para esse exercício vai se diluindo de modo cada vez mais rápido e mais cedo na formação inicial do professor. As dimensões técnicas da prática de ensino passam a ocupar um lugar central, em detrimento de seus próprios fundamentos. Privilegia-se a forma mutilada de conteúdo! (grifos do autor).

Nesse sentido, como se solidifica a formação desses "intelectuais" se não há apropriação da base teórica ligada à futura atuação profissional? Qual a qualidade do serviço prestado à sociedade? Como serão capazes de formar sujeitos críticos e atuantes? Sob esta qualidade de formação inicial não será possível formar este tipo de sujeito. As crianças passarão pela escola, mas há muita chance de manterem seus discursos e práticas embasados no senso comum, na ausência de reflexão, no moralismo religioso, no preconceito e na manipulação.

Nessa direção, elementos centrais do processo educativo, como os conteúdos científicos, a reflexão, a criticidade, a formação humana e a transformação social, ao invés de integrarem a ação educativa, perdem valor e espaço para instâncias como os conhecimentos tácitos, a resolução de problemas do cotidiano, adaptação aos contextos sociais e formações superficiais. Ressaltamos que, idealmente, estes aspectos estariam integrados no processo educativo, conforme destaca Duarte (2010, p. 38), ao explicar que:

Se o conhecimento mais valorizado na escola passa a ser o conhecimento tácito, cotidiano, pessoal, então o trabalho do professor deixa de ser o de transmitir os conhecimentos mais desenvolvidos e ricos que a humanidade venha construindo ao longo de sua história. O professor deixa de ser um mediador entre $o$ aluno e o patrimônio intelectual mais elevado da humanidade, para ser um organizador de atividades que promovam o que alguns chamam de negociação de significados construídos no cotidiano dos alunos.

Haddad e Pereira (2013) argumentam que um professor intelectual requer, em seu processo formativo, compreender o contexto social e o quanto este afeta o âmbito escolar. Também necessita se apropriar dos conhecimentos relacionados à educação de um modo geral e, igualmente, dos conhecimentos específicos de sua área, das estratégias e metodologias de ensino eficientes.

Embasados em Saviani (1997), refutamos a ênfase dada aos conhecimentos empíricos na formação docente e no cotidiano escolar e destacamos, para o exercício da função docente, o domínio dos conteúdos específicos da área de atuação, dos conhecimentos didáticocurriculares, pois o professor terá o desafio e a necessidade de organizar os conteúdos adequados ao processo de ensino e aprendizagem. Isto posto, o domínio dos procedimentos de ensino para o trabalho com os conteúdos específicos, é essencial ao trabalho pedagógico da professora da Educação Infantil.

$O$ autor ressalta ainda a relevância da apropriação do saber pedagógico, dos conhecimentos das ciências da educação, das teorias educacionais para que o docente seja capaz de "[...] articular os fundamentos da educação com as orientações que se imprimem no trabalho educativo" (SAVIANI, 1997, p. 134). Além disso, uma compreensão do contexto social que determina a tarefa pedagógica torna-se imprescindível para que o professor possa identificar as necessidades socio-históricas e contemplá-las no processo educativo.

$O$ pesquisador explica ser substancial o domínio das atitudes intrínsecas à atribuição do professor, das competências específicas à identidade desse profissional para completar o processo formativo docente. Dentre outras, destacam-se "[...] a disciplina, pontualidade, coerência, clareza, justiça e equidade, diálogo, respeito as pessoas dos educandos e atenção as suas dificuldades" (SAVIANI, 1997, p. 136). Somente após a internalização destes conhecimentos supracitados, o professor torna- 
se preparado para organizar propostas educativas transformadoras, articuladas aos interesses da população. Para Saviani (1997, p. 140):

[...] o exercício pleno dessa função, é mister que o conhecimento seja produzido previamente no professor de forma sistemática como condição para que ele possa, de forma deliberada e também sistemática desenvolver o processo de produção do conhecimento nos alunos. Por essa via, será possível não apenas o domínio de novos conhecimentos por parte dos alunos, produzindo-se neles esses conhecimentos, mas a partir dessa base se viabilizará também a produção de novos conhecimentos no âmbito da sociedade, contribuindo, assim, para - avanço do saber do ponto de vista das relações históricos sociais da comunidade.

Diante desse pressuposto, caso a formação inicial do professor não tenha sido a mais adequada, estariam sua carreira e papel social condenados a um desempenho medíocre? Certamente, não podemos negar que essa seja uma grave dificuldade que afeta não só o professor, mas também as crianças e a sociedade como um todo. Torna-se um problema complicado, inclusive para ser sanado, o qual demanda tempo para leitura, estudo e predisposição por parte do professor para rever suas crenças e atitudes relacionadas. Diante da realidade enfrentada pelos docentes frente às condições inadequadas de trabalho, baixos salários, jornada dupla para melhoria da renda familiar, as exigências para o desenvolvimento profissional tornam-se difíceis de serem alcançadas perante tamanho desgaste físico e psicológico sofrido por estes profissionais na contemporaneidade.

Entretanto, a formação continuada, quando projetada para a realidade de determinado grupo docente, pode ser uma das saídas possíveis para a redução dos desafios decorrentes de uma formação inicial insuficiente ao exercício profissional na perspectiva da abordagem teórica discutida e embasadora desta tese. Ainda assim, não cremos que a formação continuada se reduza ao cuidado das defasagens deixadas pela formação inicial, pois o exercício do magistério na cotidianidade interpõe muitas questões que precisam ser atendidas para que os professores possam desempenhar sua função social e pedagógica junto às crianças e à sociedade.

Em tempo, o conceito de formação continuada docente adotado na presente tese é compreendido como o processo contínuo de melhoramento do ato de ensinar, o qual postula aprofundamento teórico e prático por parte dos professores a respeito dos conhecimentos científicos e culturais e a adoção de práticas educativas inovadoras, firmadas num referencial teórico consistente em relação às exigências do ato de ensinar na contemporaneidade.

Adotamos o materialismo históricodialético como fundamentação teórico-prática do processo de formação continuada da professora pré-escolar por acreditarmos que este, ao estruturar o ato formativo com base nos dados concretos da realidade estudada, visando contemplar as necessidades mapeadas, aumenta as chances de obtenção de resultados positivos, já que ele trabalha sobre o plano concreto/materializado e não no plano idealista.

Desse modo, o professor só conseguirá realizar um ato educativo humanizador se ele for um sujeito humanizado, pois ninguém oferece o que não tem, bem como não transmite adequadamente o que não sabe. Entretanto, como já destacamos, as formações docentes estão cada vez mais debilitadas por influência de relações/interesses sociais mais amplos, o que compromete a humanização de professores e alunos e concomitantemente de toda uma classe. Estas carências deliberadas nos processos formativos dos professores, juntamente a desvalorização social de seu papel desencadeia uma supressão na identidade destes profissionais, ao ponto de desacreditarem na relevância de sua função para a sociedade e atuarem sem um mínimo de compromisso ético e político.

Embasados nas discussões trazidas por Mazzeu (1998), destacamos que o processo de formação continuada proposto se norteia pelo conceito de humanização. Podemos afirmar isto, 
visto que, ao possibilitar à docente participante a reflexão crítica sobre a realidade educacional nacional e local e a partir das conclusões desta reflexão, ela pode escolher/acolher os conhecimentos necessários à sua autonomia e emancipação.

Esse conceito possibilita uma compreensão mais ampla e profunda dessa formação do que outros conceitos como o de profissionalização, quer essa profissionalização seja entendida sob um enfoque funcionalista (como um equiparação do professorado a categorias profissionais com mais vantagens no âmbito da sociedade atual, como os médicos, por exemplo) quer essa profissionalização seja compreendida apenas como aquisição de uma postura prático-reflexiva ou crítico-reflexiva, na qual não seja dado o devido peso ao processo de apropriação, pelo professor, do saber acumulado historicamente (MAZZEU, 1998, não paginado).

0 processo humanizador de formação permite ainda ressaltar a relevância da função social do professor e de resgatar os reais sentidos e significados do trabalho docente da participante de nosso estudo, resistindo às relações de dominação existentes na sociedade. Dessa maneira, no processo de formação continuada desenvolvido, possibilitamos à professora pré-escolar o acesso a uma concepção dialética de educação e formação humana; a uma formação ético e política, a qual pretende a superação da divisão de classes e das injustiças decorrentes desta, e a organização de uma prática educativa humanizadora por meio do brinquedo e da brincadeira.

À vista disso concluímos que as mazelas decorrentes do modelo de formação docente defendido pelo Estado e pelo sistema capitalista são inúmeras e estão enraizadas nas atitudes e nas visões dos profissionais da educação de um modo geral. Consequentemente, um processo de formação continuada árduo, extenso e consistente faz-se necessário, já que os professores não demonstram solidez teórica e prática, sendo seus planejamentos alinhados frequentemente ao empirismo.

Outra problemática que destacamos relaciona-se ao posicionamento dos profissionais da Secretaria Municipal diante do processo formativo continuado. Hesitamos em afirmar se esta realmente compactua com as medidas/estratégias formativas ou as consente para não contradizer afirmativas recorrentes acerca da melhoria da qualidade do ensino ofertado às crianças. Encontramos uma total liberdade para trabalharmos as propostas organizadas, no entanto, não percebemos um interesse efetivo no sentido de identificar sua dinâmica, seus resultados, refletir coletivamente a ponto de expandir algumas das conquistas alcançadas aos demais professores.

Apoiados na Psicologia Histórico-Cultural e Pedagogia Histórico-Crítica, defendemos uma formação de professores robusta, que alinhe teoria e prática e que desenvolva a responsabilização pelo processo de evolução das crianças. Nessa ótica, a formação continuada humanizadora com uma professora pré-escolar buscou evidenciar a importância de sua atuação pedagógica sobre o desenvolvimento infantil. Além disso, e por esta razão, sua ação educativa depende de ser minuciosamente planejada e engendrada sob os conhecimentos historicamente construídos, dentre eles: o brinquedo e a brincadeira de papéis sociais, que são os elementos potencializadores da emancipação psíquica das crianças desta faixa etária, segundo a abordagem teórica selecionada.

Ancorados na Pedagogia Histórico-Crítica

e na Psicologia Histórico-Cultural, as quais, segundo Pasqualini (2013, p. 72), "são duas ciências que se relacionam de tal modo que o objeto de uma é condição para outra", já que, para a organização do processo educativo, é indispensável a compreensão sobre o desenvolvimento do psiquismo, como também para apreender intelectualmente o decurso do desenvolvimento mental humano, é essencial articulá-lo ao processo educativo e à apropriação do conhecimento historicamente construído. Desse modo, a autora evidencia que a Psicologia e a Pedagogia requerem pensamentos coadunantes.

Conhecer o estado atual da(s) criança(s) implica conhecer o período de desenvolvimento em que se encontra(m) a(s) criança(s), o que indica o que é esperado em termos de seu funcionamento psíquico e comportamental. Esse conhecimento orienta a seleção de conteúdos de ensino e definição de objetivos pedagógicos de acordo com a faixa etária ou, mais precisamente, com o período do desenvolvimento da criança (PASQUALINI, 2010, p. 120).

As novas capacidades e funções mentais só serão alcançadas por meio do ato educativo, que, segundo Saviani (2013), consiste na complexa ação de selecionar intencionalmente os conteúdos, visando a humanização e as formas 
de ensino, que são as estratégias mais assertivas para atingir gradualmente as finalidades pedagógicas.

Nessa perspectiva, Martins (2013) ressalta que o planejamento de ensino depende da conexão entre a tríade forma-conteúdodestinatário, pois, para escolher conscientemente os conteúdos e as formas a serem trabalhados, deve-se conhecer a criança e reconhecê-la com um ser em desenvolvimento, que apresenta em cada período da vida maneiras distintas de interação com o mundo. Para a autora,

O trabalho pedagógico
orienta-se pelo
conhecimento acerca das
características que a
criança já dispõe na
contraposição àquelas que
ainda não existem - mas
visamos formar; toma
como ponto de partida os
conhecimentos que a
criança já possui e
articula-os aquilo que ela
não domina - mas deve
dominar; elegendo
procedimentos e recursos
que se firmam como
práxis educativa, isto é,
como ineliminável
articulação entre teoria e
prática (MARTINS, 2013, p.
19).

Nesse mesmo sentido, Arce e Jacomeli (2012, p.1-2) destacam que:

Ao trabalhar-se
intencionalmente com
essa criança explorando as
características que
marcam essa etapa do seu
desenvolvimento
biológico, psicológico,
cultural e social, estamos
iniciando um processo de
escolarização, um
processo de compreensão,
apreensão, descoberta do
mundo que nós seres
humanos construímos.

Destarte, o ato educativo histórico-crítico pauta-se no ensino dos conhecimentos historicamente construídos, os quais precisam estar articulados ao contexto social contemporâneo e serem adequados aos níveis de desenvolvimento das crianças atendidas. Esses conhecimentos científicos, fundamentais ao processo de humanização das crianças, são transformados em conhecimentos pedagógicos para uma apropriação satisfatória.

0 processo de apropriação dos conhecimentos científicos, da teoria que explica a prática e a modifica, requer, uma série de funções, como a atenção arbitrária, a memória lógica, a abstração, a comparação e a discriminação. Vigotiski (2000), ao abordar esse tema na relação com o processo de escolarização, discute que o ensino direto de conceitos sempre se mostra estéril. O professor que se utiliza somente do recurso da exposição oral, do puro verbalismo, obterá, por parte do aluno, apenas uma assimilação vazia do conteúdo trabalhado. O professor necessita, portanto, conforme afirma Saviani (2013), converter o saber objetivo em saber escolar, de modo que o torne assimilável para o aluno, de tal forma que este passe gradativamente do não-domínio ao domínio dos conhecimentos científicos. 0 docente deve partir do conhecimento sincrético, desorganizado do aluno, para chegar ao conhecimento sintético, sistematizado e vinculado a prática social (FACCl, 2004, p. 236237).

O professor, de posse desses conhecimentos, organiza sua prática educativa a partir da prática social e de suas especificidades, nesse contexto de uma sociedade capitalista e na luta de classes. Ele dimensiona o que a criança já sabe com o que ele deseja que ela saiba; o que ela é com o que ele deseja que ela venha a ser. É nesta tensão dialética que o processo formativo se estabelece, visando sempre a emancipação dos sujeitos e a transformação da realidade. A tarefa educativa envolve, portanto, uma posição e intenção política, conforme destaca Abrantes (2018, p. 101), ao afirmar que:

A prática social tomada
comor referência
organizadora do processo
metodológico da atividade
educativa implica num
posicionamento sobre a
relação sociedade,
indicando a necessidade
de compreensão
sistemática sobre o modo
de produzir e reproduzir
social e a função que
desempenha a instituição


escolar nas formações sociais que se inserem.

Dessa forma, durante suas aulas, o professor problematiza a transformação dos conhecimentos científicos complexos (essenciais a formação dos estudantes) em conhecimentos pedagógicos adequados aos níveis de desenvolvimento dos estudantes, tornando-os assim mais fáceis de serem compreendidos e apropriados. Possibilita ainda a relação direta/vivência dos estudantes com os conhecimentos elaborados e, caso essa instrumentalização seja bem sistematizada, permite a compreensão do fenômeno estudado e um salto qualitativo no desenvolvimento dos estudantes (catarse).

Saviani $(2011 ; 2013)$ revela que o método de ensino da Pedagogia Histórico-Crítica parte da problemática existente na prática social, a qual é similar ao professor e aos alunos, existindo apenas uma diferença quanto ao grau de compreensão dos mesmos sobre o fenômeno. $O$ professor é considerado mais experiente e portador de uma visão mais ampliada e, portanto, é sua função escolher os conteúdos e as formas mais adequadas ao nível de desenvolvimento da criança para que esta supere seu conhecimento anterior e se aproxime do nível de conhecimento do docente por meio das vivências educativas, experiências dialéticas entre as crianças e o professor e entre estes e o conhecimento. Já que a criança, por sua vez, apresenta uma visão empírica da realidade, Teixeira (2013, p. 30) destaca que:

[...] uma visão superficial, pautada em impressões imediatas, imprecisas e fragmentárias, não basta para analisar criticamente as situações ou os problemas que se apresentam a dinâmica do trabalho educativo. É necessário que se vá ao fundamento, as bases que Ihes dão sustentação o que determinam sua manifestação como fenômeno na realidade.

Vigotski (2001) afirma que, ao falarmos em ensino, tratamos de um ensino que promove o desenvolvimento. Sendo assim, segundo o autor, um ensino de qualidade é aquele que conduza ao progresso mental; que trabalha sobre a zona de desenvolvimento próximo/iminente da criança, configurada num processo dialético; que garanta momentos de aprendizagens e avanços na formação global dos educandos.

A zona de desenvolvimento iminente é compreendida como a distância entre o que a criança consegue realizar sozinha (zona de desenvolvimento real - ZDR) e o que ela consegue realizar com ajuda dos adultos ou de crianças mais experientes (zona de desenvolvimento potencial - ZDP). Segundo Trindade (2010), revela ainda dados importantes a serem utilizados pelo professor no processo educativo, ao indicar o nível de desenvolvimento das crianças num determinado período, ajudando, assim, no planejamento de estratégias para evolução do desenvolvimento infantil.

A zona de desenvolvimento iminente permite-nos, assim, delinear o futuro da criança e seu estado dinâmico de evolução, propiciando o acesso não somente ao que já foi atingido por meio do desenvolvimento, como também àquilo que está em processo de amadurecimento (VIGOTSKI, 1991).

Dessa maneira, as crianças não aprenderão e não se desenvolverão se o seu contexto não the for profícuo, o mesmo sendo válido para a criação da necessidade de aprender. Na prática educativa histórico-crítica, o professor necessita ter sempre finalidades pedagógicas claras, motivos reais para a organização e proposição das atividades. Ele carece ser diretivo e articular dialeticamente a forma e o conteúdo aos interesses e às necessidades das crianças (destinatários).

Os interesses infantis são compreendidos pelas teorias adotadas como vontades e/ou desejos das crianças, os quais, assim como os motivos e as necessidades, estão estreitamente relacionadas aos estímulos recebidos pelas crianças, sendo resultantes das relações com os sujeitos e o ambiente vivido.

Conforme destaca Arce (2013, p. 21):

[...] os motivos estão ligados as características do desenvolvimento da vontade do sujeito, que constituem-se em processo longo, marcado pelas relações estabelecidas com os adultos, estando 
intimamente ligados à construção dos significados, dos sentidos. Construção esta que se aprofunda à medida que a criança é inserida no mundo.

De acordo com Vigotski (1991), o ato educativo deve considerar tais interesses infantis. Contudo, estes não podem constituir-se em suas finalidades. Tal ato engloba os interesses infantis, mas depende também da direção do professor ao propor atividades emancipatórias. Se ocorrer contrariamente a isto, deixa de ser educativo. Cabe, então, ao professor estimular adequadamente as crianças para propiciar acesso aos elementos mais enriquecedores da sociedade.

Saviani (2013) destaca que, algumas vezes, os conteúdos propostos pelo professor podem não agradar às crianças de modo imediato, desmotivando-as e gerando recusas. Elas podem apresentar outros desejos e vontades imediatas, relacionados aos conhecimentos tácitos, pois as crianças não têm consciência do que é mais importante para elas e para o seu desenvolvimento.

O professor, diante disso e de acordo com a perspectiva em discussão, não deve apenas seguir as crianças, por ser o mais fácil ou menos trabalhoso, negligenciando assim a sua função. Pelo contrário, acerta ao cumprir a sua função e despertar nas crianças o interesse pela realização das tarefas, para o processo de aprendizagem, sem chantagens, imposição de prêmios e/ou castigos, mas pela adoção de metodologias que desencadeiem progressivamente o apreço pelo aprender e pelo conhecimento.

Leontiev (1978b) aponta que as necessidades reais humanas não são inatas, mas circunscritas pelo conteúdo cultural, consistindo na formação dos motivos reais da aprendizagem a meta pedagógica motriz.

Os motivos, não são, de fato, reconhecidos pelo sujeito e quando executamos uma ação ou outra, naquele momento usualmente não nos damos conta dos motivos que evocam a ação. É certo que não é difícil para nós atribuir motivação a ela, mas a motivação nem sempre contém em si uma indicação de seu motivo verdadeiro (LEONTIEV, 1978b, s/p).
O autor afirma que os motivos são os impulsionadores e orientadores das atividades, alterando-se a cada nova etapa do desenvolvimento humano. Ressalta ainda ser complexo compreender o que consiste efetivamente em motivos das ações da criança, os quais são geradores das atividades e o que são meros desejos, paixões e/ou vontades infantis (LEONTIEV, 1978b).

Os motivos, no entanto, não estão separados da consciência. Mesmo quando os motivos não são reconhecidos, isto é, quando o ser humano não se dá conta do que o faz realizar uma ação ou outra, eles ainda encontram seu reflexo psíquico, mas de uma forma especial - na forma da coloração emocional da ação. Esta coloração emocional (sua intensidade, sua marca e seu caráter qualitativo) exerce uma função específica, que também requer a distinção entre o conceito de emoção e o conceito de sentido pessoal. Sua não-coincidência não se dá, no entanto, por natureza; evidentemente, nos níveis inferiores, os objetos da necessidade são exata e diretamente "marcados" pela emoção. A nãoconformidade só aparece como resultado da quebra da função dos motivos que ocorre no curso do desenvolvimento da atividade humana (LEONTIEV, 1978b, p. 265).

Leontiev (1978a) explica que a necessidade leva à atividade, e esta leva à satisfação da necessidade. Todavia, nem sempre as crianças terão clareza dos motivos verdadeiros da atividade humana, podendo encontrar outros motivos para sua realização, como por exemplo, ganhar nota pela concretização da ação, ou seja, estar livre depois da materialização da ação. Por consequência, as ações não correspondem aos objetivos e estas se tornam apenas tarefas, as quais não são realizadas com satisfação, com emoções positivas. Os motivos para a realização das ações propostas são, então, somente estímulos suplementares.

Desta forma, certos motivos que induzem a atividade também lhe dão sentido pessoal; vamos chamá-los de motivos formadores de sentido. Outros que coexistem com eles e exercem o papel de fatores de estimulação (positiva ou negativa), às vezes fortemente emocionais e afetivos, não têm a função da formação de sentido; chamaremos esses motivos literalmente de motivos-estímulos. Caracteristicamente, quando uma atividade, importante em seu próprio sentido pessoal para o homem, encontra, no curso de sua realização, 
um estímulo negativo que elicia, até mesmo, uma experiência emocional forte, então seu sentido pessoal não se altera por causa disso; muito frequentemente, uma outra coisa acontece: especificamente, ocorre, de forma única, um rápido descrédito da emoção eliciada. Este fenômeno bem conhecido leva-nos a pensar, mais uma vez, no problema das relações entre as experiências emocionais e o sentido pessoal (LEONTIEV, 1978b, p. 323).

Vigotski (1996) menciona, assim, que, em cada momento da vida, temos uma neoformação que norteia todo processo de desenvolvimento e reestrutura a personalidade humana sobre um novo alicerce.

Percebemos, portanto, que as neoformações são oriundas dos contextos sociais das crianças, dos estímulos e dos acessos culturais, bem como das relações que estabelecem com estes.

Mukhina (1996) aponta, no entanto, que embora novas ações possam enriquecer o mundo infantil e fomentar o surgimento de novas atividades-guias, isso não se efetiva concretamente caso a criança não desperte interesse pelo universo adulto, pela reprodução de suas funções sociais. Assim sendo, "a passagem para uma nova atividade principal depende de todas as condições de vida da criança na sociedade, não apenas do que o adulto the ensina" (MUKHINA, 1996, p. 45, grifos da autora). Nesse aspecto, Mukhina (1996) e Leontiev (2001) evidenciam que o desenvolvimento não se dá de modo linear, mas, ora em períodos mais vagarosos, ora em períodos mais incisivos. Estes últimos são denominados, pelos autores, como crises de desenvolvimento, ou seja, são momentos de mudanças bruscas, períodos críticos que caracterizam os saltos qualitativos da psique infantil, os quais resultarão em alterações do tipo de atividade-guia, podendo ocasionar alterações de comportamento. Porém, é importante ressaltarmos que essas crises podem ser evitadas se a formação psíquica ocorrer num processo estável.

Assim, a cada período da vida, há a predominância de um tipo de atividade ${ }^{3}$, denominada de atividade-guia, caracterizada pela

\footnotetext{
3 "Por atividade, designamos os processos psicologicamente caracterizados por aquilo a que o processo, como um todo, se dirige (seu objeto), coincidindo sempre com o objetivo que estimula o sujeito a executar esta atividade, isto é, o motivo" (LEONTIEV, 2001, p. 68).
}

principal forma de relacionamento da criança com a realidade e como atividade que mais contribui para o desenvolvimento humano. Isto não significa que as demais atividades não promovam o desenvolvimento, mas que apresentam uma relevância secundária. Conforme Leontiev (2001), a alteração de uma atividade-guia para outra não está diretamente relacionada à idade cronológica da criança, mas aos motivos e aos objetivos infantis.

O desenvolvimento de sua consciência encontra expressão em uma mudança na motivação de sua atividade; velhos motivos perdem força estimuladora, e nascem novos, conduzindo a uma reinterpretação de suas ações anteriores. A atividade que costumava desempenhar o papel principal começa a se desprender e a passar para um segundo plano. Uma nova atividade surge, e com ela começa também um novo estágio de desenvolvimento (LEONTIEV, 2001, p. 82).

Para Pasqualini e Abrantes (2013, p.16), a atividade-guia é a maior potencializadora "[...] do desenvolvimento das capacidades e funções psíquicas superiores humanas [...] de complexificação da atividade infantil em termos da mudança de seu conteúdo e estrutura que, a cada novo período, faz avançar o psiquismo infantil produzindo neoformações".

Dessa maneira, para haver aprendizagem efetiva, torna-se necessário que a criança esteja em atividade, que consiste na conexão estabelecida entre a criança, as finalidades de suas ações (encadeadas) e o motivo/objeto de sua atividade. As crianças precisam estar efetivamente envolvidas com o objeto; caso contrário, estas só terão contato com o conhecimento novo, que servirá meramente como elementos de informação e não de formação.

Assim, a primeira característica do estar em atividade é a coincidência entre motivo e resultado da atividade. A segunda característica é a condição psicológica favorável dada pelo afeto que é condicionado pela necessidade ao encontrar a possibilidade de ser satisfeita. A presença de um motivo para o fazer da criança que possa ser respondido na atividade é, portanto, condição para o desenvolvimento (MELLO; LUGLE, 2014).

Duarte (2013) pondera que, quando essa atividade se fragmenta e se constitui apenas em 
ações $^{4}$ deixa de existir uma ligação entre o resultado e o motivo da ação, com a necessidade que leva a criança a agir, o processo de aprendizagem inexiste. Essa se torna uma ação vazia, sem eficiência no ato educativo.

Nessa perspectiva, Facci (2004, p. 247) ressalta que:

O professor, conforme asseveram Nunes e Pacheco (1997), deve estar atento ao que motiva a aprendizagem do aluno e também criar motivos internos para a atividade de aprendizagem. Ao mesmo tempo em que ele motiva o aluno, também deve estar atento ao que o motiva, o que incita seu trabalho, ou seja, qual é o sentido pessoal da atividade que ele executa. A unidade básica do trabalho docente seria o sentido que têm, para o professor, as ações que ele realiza em seu trabalho. A ruptura entre significado e sentido caracteriza a alienação.

Por isso, não é incomum observarmos no ambiente escolar crianças obtendo sucesso nas propostas. Contudo, sem demonstração de satisfação pela conquista, já que a realização das tarefas é mecânica e o cumprimento dos protocolos forçados para não serem punidas, muitas vezes, resultam-se em ações vazias, sem a garantia de aprendizagens efetivas. $O$ aprendizado, então, só ocorrerá se a criança for afetada pela proposta pedagógica e se esta fizer sentido para ela. Segundo Leontiev (1978a, p. 351), "uma atividade sem sentido, é uma 'carga morta', um fardo psicológico. O sentido pessoal nasce na atividade motivada, na vivência dos interesses, na articulação entre os meios e fins de tudo que fazemos".

Vigotski (1996) complementa esta discussão ao assinalar que a aprendizagem não se

\footnotetext{
${ }^{4}$ Um ato ou uma ação é um processo cujo motivo não coincide com seu objetivo (LEONTIEV, 2001 p. 69).
}

desencadeia somente pelo ouvir ou pelo fazer, mas pela vivência da criança com o conhecimento, envolvendo um movimento dialético entre meio e sujeito, denominado como perejivanie.

Para Vigotski (1996), a vivência é uma unidade entre as especificidades da criança e a situação social. É uma relação exclusiva entre estes. Sendo assim, um ambiente apresenta sentidos diferentes para as crianças e estes sentidos ainda podem se alterar em fases diferentes da vida delas, pois suas especificidades estão em jogo. Segundo ele "[...] perejivanie deve ser entendida como uma relação interna da criança como uma pessoa com um outro aspecto da realidade" (VIGOTSKI, 2004, p. 188). Ela é concebida como uma vivência dialética entre os sujeitos e os elementos sociais a ponto destes aprenderem e se desenvolverem nos processos de experimentações; logo, a perejivanie é um momento de aprendizado que ajuda na formação e na emancipação dos sujeitos.

O processo de aprendizagem efetivado é de extremo valor para as teorias adotadas, por entenderem que este precede o desenvolvimento humano e, consequentemente, a sua ausência ou deficiência replicará um desenvolvimento inadequado.

Elkonin (1998) explica que, segundo a Psicologia Histórico-Cultural, até um ano de idade, a atividade-guia para a criança é a comunicação emocional com os adultos, visto que, nesse período, a criança, mesmo sem saber manipular os objetos ou falar, interage e se comunica com os adultos por meio das emoções e dos movimentos (sorrisos, olhares, expressões). Aponta, contudo, que os objetos também se encontram presentes na vida da criança, pois o mundo adulto está repleto de objetos, entre os quais, alguns são produzidos especialmente para as crianças, possibilitando-lhes a aprendizagem de algumas habilidades humanas.

Conforme Elkonin (1998), de um ano até os três anos de vida, a atividade-guia para a criança é a atividade objetal-manipulatória, ou seja, o interesse que anteriormente voltava-se para o adulto, agora se destina aos objetos. Nesse momento, as crianças querem ampliar seus conhecimentos sobre o mundo e o fazem por meio da interação com objetos sociais mediada pelos adultos.

No período dos três aos seis anos de idade, a atividade-guia passa a ser o jogo de papéis sociais ou brincadeira de papéis sociais. 
Nesta etapa, de acordo com Leontiev (1978b), a criança quer ser como o adulto. Porém, como não pode satisfazer seus interesses e necessidades no plano real, utiliza a imaginação, o faz de conta para representar os papéis sociais desempenhados pelos adultos e assim compreender melhor o universo que a rodeia.

Lopéz e Goméz (2005) afirmam que esses períodos sensíveis de desenvolvimento, nos quais 0 ato educativo desempenha maior efeito sobre as capacidades psíquicas em formação, são denominados de periodização, assinalando que, se não houver os estímulos necessários durante estes períodos, é possível que as capacidades ou funções humanas não se formem ou então se desenvolvam insatisfatoriamente.

Diante do exposto, pode surgir a seguinte reflexão transversal a este estudo: A criança necessita vivenciar as produções históricas e culturais para se tornar efetivamente humana. A brincadeira de papéis sociais é reconhecida como a atividade-guia na idade pré-escolar, a mais eficiente na formação da psique. Entretanto, não é qualquer tipo de brincadeira que possibilita a humanização, mas aquela que é enriquecida e complexificada adequadamente aos níveis de desenvolvimento das crianças. Conforme ressalta Sena (2018, p. 189), "ao possibilitar às crianças o acesso à brincadeira de papéis de modo consciente, o professor pré-escolar desempenha [...] sua função social de contribuir para o alcance do desenvolvimento do psiquismo infantil em suas máximas possibilidades". Na esteira desse raciocínio, a adequada intervenção pedagógica justifica e dota de sentido a real função da escola e do professor dessa etapa educativa.

\section{CONSIDERAÇÕES FINAIS}

Sob esta perspectiva, concluímos respaldado nas premissas da Pedagogia HistóricoCrítica e da Psicologia Histórico-Cultural, que é possível, no bojo do processo de formação continuada com uma professora pré-escolar, organizar práticas educativas humanizadoras à luz do materialismo histórico-dialético e do emprego do brinquedo e das brincadeiras de papéis sociais para que uma formação infantil de qualidade seja garantida a todas. Para tal, é indispensável que o papel do professor conheça as particularidades e os períodos de desenvolvimento das crianças para que $o$ ato educativo seja planejado com objetivos e formas adequadas às necessidades das crianças, com o intuito de maximizar suas aprendizagens.
Demonstre uma compreensão sobre a aprendizagem infantil como dependente da mediação do adulto e da atuação sobre a atividade-guia do desenvolvimento omnilateral da criança, encare a brincadeira de papéis sociais como atividade fundamental ao processo educativo pré-escolar, a fim de ensinar as crianças a pensar e a se desenvolver com a ajuda do professor, que, compartilhando a brincadeira com a criança, possibilita avanços, por meio de desafios e de reflexões.

\section{REFERÊNCIAS}

ABRANTES, A. A. Como ensinar?: o método da pedagogia histórico-crítica e a aula como unidade concreta de relações sociais. In: PASQUALINI, J. C; TEIXEIRA, L. A; AGUDO, M de M. Pedagogia histórico-crítica: legado e perspectivas. Uberlândia: Navegando Publicações, 2018. p. 99116.

ARCE, A. Interações ou brincadeiras? afinal o que é mais importante na educação infantil? e o ensino como fica? In: ARCE, A. (Org.) Interações e brincadeiras. Campinas: Editora Alínea, 2013. p. 17-39.

ARCE, A.; JACOMELI, M. R. M. Educação infantil versus educação escolar?: entre a (des) escolarização e a precarização do trabalho pedagógico nas salas de aula. Campinas: Autores Associados, 2012.

BRASIL. Ministério da Educação e do desporto. Referencial curricular nacional de educação infantil. Brasília: MEC/SEF, 1998. 253 p. v.3

BRASIL. Ministério da Educação. Secretaria de Educação Básica. Diretrizes curriculares nacionais para a educação infantil. Brasília: MEC/SEB, 2010.

COSTA, A. Entre a dilapidação moral e a missão redentorista: o processo de alienação no trabalho dos professores do ensino básico brasileiro. In: COSTA, Á; FERNANDES, N. E.; SOUZA, G. A proletarização do professor: neoliberalismo na educação. São Paulo: Instituto José Luís e Rosa Sundermann, 2009. p. 59-100.

DUARTE, N. A escola de Vigotski e a educação escolar: algumas hipóteses para uma leitura pedagógica da psicologia histórico-cultural. 
Psicologia USP, São Paulo, v. 7, n. 1/2, p. 17-50, 1996.

DUARTE, N. A anatomia do homem é a chave da anatomia do macaco: a dialética em Vigotski e em Marx e a questão do saber objetivo na educação escolar. Educação e Sociedade, Campinas, v. 21, n. 71, p. 79-115, 2000.

DUARTE. N. O debate contemporâneo das teorias pedagógicas. In: MARTINS, L. M; DUARTE, N. (Orgs.). Formação de professores: limites contemporâneos e alternativas necessárias [online]. São Paulo: Editora UNESP. São Paulo: Cultura Acadêmica, 2010. p. 33- 49. https://doi.org/10.1590/s0101-

\section{4}

DUARTE. N. Sociedade do conhecimento ou sociedade das ilusões. Campinas: Autores Associados, 2013.

DUARTE. N. Os conteúdos escolares e a ressurreição dos mortos: contribuição à teoria histórico-crítica do currículo. Campinas: Autores Associados, 2016.

EIDT, N. M.; DUARTE, N. Contribuições da teoria da atividade para o debate sobre a natureza da atividade de ensino escolar. Psicologia da Educação, São Paulo, n. 24, p. 51-72, 2007.

ELKONIN, D. B. Psicologia do jogo. São Paulo: Martins Fontes, 1998.

FACCI. M, G. D. A periodização do desenvolvimento psicológico individual na perspectiva de Leontiev, Elkonin e Vigostski. Caderno Cedes, Campinas, v. 24, n. 62, p. 64-81, $2004 . \quad$ https://doi.org/10.1590/S010132622004000100005

HADDAD, C. R. PEREIRA. M. F. R. Pedagogia histórico-crítica e psicologia histórico cultural: inferências para a formação e o trabalho de professores. Germinal: Marxismo e Educação em Debate, Salvador, v. 5, n. 2, p. 106-117, 2013. https://doi.org/10.9771/gmed.v5i2.9703

LEONTIEV, A. N. O desenvolvimento do psiquismo. Lisboa: Livros Horizonte, 1978a.
LEONTIEV, A. N. Actividade, consciência e personalidade. Portugueses Edition: Domínio Público, 1978b.

LEONTIEV, A. N. Os princípios psicológicos da brincadeira pré-escolar. In: VYGOTSKI. L. S; LURIA, A. R; LEONTIEV, A. N. Linguagem, desenvolvimento e aprendizagem. São Paulo: EDUSP, 2001. p. 119-142.

LOMBARDI, J. C. Notas sobre a educação da infância numa perspectiva marxista. In: MARSIGLIA, A. C. G. (Org.). Infância e pedagogia histórico-crítica. Campinas: Autores Associados, 2013, p. 7-16.

LOPÉZ, J.; GOMÉZ, A. M. S. El proceso educativo para el desarrollo integral de la primera infancia. Havana: Celep e Unicef, 2005.

MARTINS, L. M. Especificidades do desenvolvimento afetivo-cognitivo de crianças de 4 a 6 anos. In. ARCE, A; MARTINS, L. M. (Orgs.). Quem tem medo de ensinar na educação infantil? Em defesa do ato de ensinar. Campinas: Alínea, 2007. p. 63-92.

MARTINS, L. M. Psicologia histórico-critica e psicologia histórico-cultural. In: MARSIGLIA, A. C. G. (Org.). Pedagogia histórico-critica 30 anos. Campinas: Autores Associados, 2011. p. 43-57.

MARTINS, L. M. 0 desenvolvimento do psiquismo e a educação escolar: contribuições a luz da psicologia histórico cultural e da pedagogia histórico-critica. Campinas: Autores Associados, 2013. https://doi.org/10.1590/S1414$\underline{32832012000100025}$

MARSIGLIA, A. C. G. A prática pedagógica histórico-crítica na educação e ensino fundamental. Campinas, SP: Autores Associados, 2011.

MAZZEU. L. T. B. Uma proposta metodológica para a formação continuada de professores na perspectiva histórico-social. Caderno Cedes, Campinas, v. 19, n. 44, p. 59-72, 1998. https://doi.org/10.1590/S010132621998000100006

MELLO, S. A; LUGLE, A. M. C. Formação de professores: implicações pedagógicas da teoria histórico-cultural. Revista contrapontos, v. 14, n. 
2, p.

259-272,

2014.

https://doi.org/10.14210/contrapontos.v14n2.p2 $\underline{59-274}$

MUKHINA, V. Psicologia da idade pré-escolar. São Paulo: Martins Fontes, 1996.

PASQUALINI, J. C. Princípios para a organização do ensino na educação infantil na perspectiva Histórico-Cultural: um estudo a partir da análise da prática do professor. 2010. 268f. Tese (Doutorado em Educação) - Faculdade de Ciências e Letras, Universidade Estadual Paulista, Araraquara, 2010. https://doi.org/10.9771/gmed.v5i2.9696

PASQUALINI, J. C. Periodização do desenvolvimento psíquico à luz da escola de Vigotski: a teoria histórico-cultural do desenvolvimento infantil e suas implicações pedagógicas. In: MARSIGLIA, A. C. G. (Org.) Infância e pedagogia histórico-crítica. Campinas: Autores Associados, 2013. p. 71-97.

PASQUALINI, A. C; ABRANTES, A. A. Forma e conteúdo do ensino na educação infantil: o papel do jogo protagonizado e as contribuições da literatura infantil. Germinal Marxismo e Educação em Debate. Salvador, v. 5, n. 2, p. 1324, 2013.

PRADO, A. E. F. G; AZEVEDO, H. H. O. Currículo para a educação infantil. In: ARCE. A; JACOMELI, M. R. M. Educação Infantil versus Educação escolar? Entre a (des)escolarização e a precarização do trabalho pedagógico nas salas de aula. Campinas: Autores Associados, 2012, p. 3352.

SAVIANI, D. A nova lei da educação: trajetória, limites e perspectivas. 3.ed. Campinas: Autores Associados, 1997.

SAVIANI, D. Escola e democracia. 35.ed. Campinas: Autores associados, 2011.

SAVIANI, D. Perspectiva marxiana do problema subjetividade-intersubjetividade. In: Duarte, $\mathrm{N}$. (Org.). Crítica ao fetichismo da individualidade. Campinas: Autores Associados, 2012a. p. 19-46.

SAVIANI, D. Pedagogia histórico-crítica: primeiras aproximações. 11.ed. Campinas: Autores Associados, 2013.
SAVIANI, N. Educação infantil versus educação escolar: implicações curriculares de uma (falsa) oposição. In: ARCE, A.; JACOMELI, M. R. M. Educação infantil versus educação escolar?: entre a (des) escolarização e a precarização do trabalho pedagógico nas salas de aula. Campinas: Autores Associados, 2012b. p. 53-79.

TEIXEIRA, L. Pedagogia histórico-critica: contribuições para a superação do conhecimento tácito na formação de professores. In: MARSIGLIA, A. C. G. (Org.). Infância e pedagogia histórico-crítica. Campinas: Editores Associados, 2013. p. 17-34.

TRINDADE, L. A. O brinquedo na educação infantil como promotor das culturas da infância e humanização. 2010. 170 f. Dissertação (Mestrado em Educação) - Universidade Estadual Paulista, Presidente Prudente, 2010.

VIGOTSKI. L. S. A formação social da mente. São Paulo: Martins Fontes, 1991.

VIGOTSKI. L. S. El problema del desarrolho de las funciones psíquicas superiores. Madrid: Visor, 1995.

VIGOTSKI. L. S. Obras Escogidas. Madrid: Visor, 1996.

VIGOTSKI. L. S. A construção do pensamento e da linguagem. São Paulo: Martins Fontes, 2001.

VIGOTSKI. L. S. A brincadeira e o seu papel no desenvolvimento psíquico da criança. [s. I.]: [s. n.], 2004. 34 p. Disponível em: http://www.Itds.ufrj.br/gis/A_brincadeira_seu_p apel.htm. Acesso em: 27 jul. 2008. 